\title{
Risk analysis for operating active wheelchairs in non-urban settings
}

\author{
Maciej Sydor ${ }^{1}$, Andrzej Krauss', Hanna Krauss ${ }^{2}$ \\ ${ }^{1}$ Poznań University of Life Sciences, Faculty of Wood Technology, Poznań, Poland \\ 2 Poznan University of Medical Sciences, Faculty of Medicine I, Department of Physiology, Poznań, Poland
}

Sydor M, Krauss A, Krauss H. Risk analysis for operating active wheelchairs in non-urban settings. Ann Agric Environ Med. $2017 ; 24(3)$ : 532-536. doi: $10.5604 / 12321966.1235166$

\begin{abstract}
Introduction. A wheelchair is a special vehicle designed specifically for people with walking limitations. One of the types is an active wheelchair. This is a manually propelled wheelchair, the design and structure of which maximise the mobility of its given user at the expense of accepted instability.

Objective. The aim of this study was to identify and present a hierarchy of potential incidents causing a health hazard and reducing the mobility of individuals with ambulatory disability who use active wheelchairs in non-urban settings.

Materials and methods. Information about incidents connected with wheelchair use was collected from interviews with disabled individuals, based on a questionnaire. Recorded data were analysed using the Preliminary Hazard Analysis (PHA). Results. The results comprise a list of hazards for wheelchair user with ascribed priority numbers metrising their significance. Conclusions. An ordered list of hazards connected with wheelchair operation situations is useful when designing active wheelchairs and when learning the technique of wheelchair riding.
\end{abstract}

\section{- Key words}

Independent Living, Preliminary Hazard Analysis (PHA), risk analisis, wheelchair, safety measures, Spinal Cord Injury (SCI)

\section{INTRODUCTION}

A wheelchair is an assistive device which enhances personal mobility and facilitates participation in typical daily life for a person with walking limitations (WHO definition). Wheelchairs provide an opportunity to fully participate in life for $1 \%$ of the world's population - approx. 65 million people worldwide use these medical products either permanently or temporally [1], while in Poland the number of adult wheelchair users may be estimated at 200-280 thousand people [2]. Wheelchairs are devices compensating for lost or impaired motor functions:

- stabilisation of body position;

- locomotion.

Every wheelchair consists of two engineering subsystems assembled into one structural and functional entity, i.e. the transport system (wheels, the drive, steering and braking mechanisms) and the orthotic system for body positioning (body support system - back and side supports, seat, foot rest, and other devices stabilising selected parts of the body) [3]. Wheelchairs are typically modular and their individual subassemblies are produced in several dimensional variants. Such an approach on the part of their manufacturers is a reaction to the high diversification of needs of disabled individuals using wheelchairs. Differences in users' expectations concerning wheelchairs stem from three basic facts:

a) disability predisposing to the use of wheelchairs may be permanent (congenital or acquired) or temporal (caused by disease, injury or another temporary impairment);

Address for correspondence: Maciej Sydor, Poznań University of Life Sciences, Faculty of Wood Technology, Poznań, Poland

E-mail: sydor@up.poznan.pl

Received: 14 January 2014; accepted: 13 October 2015; first published: February 2017 b) there are many types and degrees of disability;

c) anthropometric and psychomotoric characteristics of disabled individuals vary from person to person [4].

In terms of sources of energy driving wheelchairs they may be divided into those driven by:

- the power of muscles of the wheelchair user (and sometimes possibly also by the power of muscles of an assisting person) - manual wheelchairs,

- solely by the power of muscles of an assisting person, - solely by an engine (or engines) - powered wheelchairs, - a hybrid system, e.g. the power of muscles of the user and engines [3].

Most frequently wheelchairs are driven by the power of muscles of the wheelchair user with an occasional or regular application of the power of muscles of an assisting person or persons. They account for over 50\% all wheelchairs [5]. There are several types of manual wheelchairs dedicated to various uses, differing in their structure, additional auxiliary attachments (additional modules) and applied settings in the basic modules. One of the types of manual wheelchairs is called the active wheelchair. Such wheelchairs are designed to facilitate independent living for individuals with dysfunctions of the lower limbs [6]. In the case of active wheelchairs, a priority is to strengthen the locomotive function of the wheelchair at the expense of its stabilisation functions. The proper operation of an active wheelchair requires an appropriate selection of the wheelchair, its adequate configuration, and learning the proper riding technique.

Wheelchairs are used both in medical and social rehabilitation. Despite the fact that wheelchairs are regulated by specifications of many technical standards and are constructed using cutting-edge technologies, the use of a wheelchair may cause bodily injuries resulting from the non-optimal design of a wheelchair, lack of adaptation to the 
environment, or inappropriate operation of the wheelchair $[7,8,9]$.

The potential mobility provided by the use of a wheelchair depends on many factors, of which one of the most important is the type of surface. Energy required for the wheelchair to move is lowest on smooth, hardened surfaces, while it increases by as much as $40 \%$ on uneven hardened surfaces [10], whereas riding on a non-hardened surface, due to the high energy requirement, may prove to be impossible or even dangerous.

Non-urban areas are characterised by a high share of non-hardened surfaces. Providing access to non-urban areas for disabled individuals is a current civilisation challenge for modern society. At present, very little is known on the opinions and experiences of disabled individuals concerning their functioning in non-urban areas [11].

\section{OBJECTIVES}

The aim of this study is to present safety-related problems faced by users of active wheelchairs. For this purpose, two groups of wheelchair users were compared, one composed of disabled individuals functioning in non-urban settings, i.e. in areas with a minimal number of town development facilities, and the other comprising urban dwellers. Both groups included individuals with SCI disability.

In order to identify hazards a survey was conducted using a questionnaire. Identified hazards were evaluated using Preliminary Hazard Analysis (PHA).

\section{MATERIALS AND METHOD}

Quantitative research. A cohort survey was conducted on two relatively uniform research groups. Both groups met the following criteria:

- Spinal Cord Injury (SCI) at C7 or lower;

- mobility only using a wheelchair;

- use of an active wheelchair and a completed wheelchair riding course;

- active lifestyle (being a student or professional activity);

- adaptation to disability - SCI occurred at least two years before the survey.

Group 1 comprised 10 individuals living outside urbanised areas, i.e. in small towns or villages. The mean age of the respondents from the non-urban areas was 33.8 years (SD 6.5), time since SCI - 14.0 years (SD 7.0) (Tab. 1).

Group 2 was composed of 9 individuals living in a city of over 650 thousand inhabitants. The mean age of respondents was 33.2 years (SD 9.5), time since SCI - 13.1 years (SD 7.4) (Tab. 2).

The questionnaire consisted of two parts. In the first part the respondents of both groups specified situations connected with the use of an active wheelchair (from Exp.1 - Exp.12). The list of wheelchair operation-related situations: ${ }^{1}$

\section{(Exp. 1) extended static sedentary position;}

1. Wheelchair use situations $1-5$ are related to the orthotic function, situations $6-12$ - to the transporting function of the wheelchair.
Table 1. Description of subjects with Spinal Cord Injury $(\mathrm{SCl})$ - residents of rural areas

\begin{tabular}{cccccc}
\hline Subject & Age & Years post-injury & Gender & $\begin{array}{c}\text { Neurological level } \\
\text { of injury (NLI) }\end{array}$ & Effect of injury \\
\hline 1 & 34 & 16 & M & C7 & Tetraparesis \\
\hline 2 & 24 & 6 & M & T6 & Paraplegia \\
\hline 3 & 37 & 21 & M & T6 & Paraplegia \\
\hline 4 & 27 & 9 & F & C6 & Tetraparesis \\
\hline 5 & 44 & 9 & M & L1 & Paraparesis \\
\hline 6 & 41 & 26 & M & T9 & Paraplegia \\
\hline 7 & 35 & 17 & M & T12 & Paraplegia \\
\hline 8 & 36 & 20 & M & L2 & Paraplegia \\
\hline 9 & 34 & 11 & M & T10 & Paraplegia \\
\hline 10 & 26 & 5 & M & T10 & Paraplegia \\
\hline
\end{tabular}

Table 2. Description of subjects with Spinal Cord Injury $(\mathrm{SCI})$ - residents of a city

\begin{tabular}{cccccc}
\hline Subject & Age & Years post-injury & Gender & $\begin{array}{c}\text { Neurological level } \\
\text { of injury (NLI) }\end{array}$ & Effect of injury \\
\hline 1 & 29 & 12 & M & T9 & Paraplegia \\
\hline 2 & 22 & 2 & F & T4 & Paraplegia \\
\hline 3 & 35 & 17 & F & T12 & Paraplegia \\
\hline 4 & 44 & 23 & M & T9 & Paraplegia \\
\hline 5 & 31 & 8 & M & T12 & Paraplegia \\
\hline 6 & 23 & 9 & M & T10 & Paraplegia \\
\hline 7 & 50 & 21 & M & T10 & Paraplegia \\
\hline 8 & 27 & 6 & M & C7 & Tetraparesis \\
\hline 9 & 38 & 20 & M & T2 & Paraplegia \\
\hline
\end{tabular}

(Exp. 2) reaching for something;

(Exp. 3) transporting something;

(Exp. 4) transfer from the wheelchairs (and onto the wheelchair) to a bed, chair, etc.;

(Exp. 5) unassisted loading and unloading of the wheelchair from a car;

(Exp. 6) riding outdoors over a non-hardened surface;

(Exp. 7) riding outdoors over a hardened surface;

(Exp. 8) riding indoors;

(Exp. 9) passage through self-closing doors, automatic lift doors, etc.;

(Exp. 10) going up and down an obstacle such as curb; (Exp. 11) going up or down stairs with safety measures; (Exp. 12) going down or up a steep ramp.

Respondents assigned a number of incidents from a closed list to each wheelchair use situation (Inc. 1 - Inc. 13). The list of incidents comprised the following events:

(Inc. 1) accidental loss of balance, no fall;

(Inc. 2) fall together with the wheelchair or falling out of the wheelchair, no bodily harm;

(Inc. 3) wheelchair damage;

(Inc. 4) damage to or destruction of other objects;

(Inc. 5) bodily harm causing lasting pain in the shoulder girdle;

(Inc. 6) bodily harm causing lasting rachialgia;

(Inc. 7) bodily harm causing lasting chiralgia;

(Inc. 8) bodily harm causing lasting pain in the elbow joint;

(Inc. 9) injury to the hand(s); 
(Inc. 10) injury to feet;

(Inc. 11) injury to the back;

(Inc. 12) injury to the buttocks;

(Inc. 13). Falling out of the wheelchair combined with another serious injury.

In the second part of the questionnaire, respondents from both groups evaluated the level of problems connected with each of the incidents. In this part, the responses of both groups were treated jointly.

Preliminary Hazard Analysis. Preliminary Hazard Analysis is one of the recommended methods in the evaluation of hazard connected with the use of medical products [12]. Based on the results of the questionnaire survey for each incident, the probability of its occurrence was established on a 5-point scale, as well as potential effects to be suffered when this incident occurs. Table 3 presents the adopted 5-point scale of hazard probability.

Table 4 contains information on values of assumed indices of incident effects.

Table 3. Frequency classes [13]

\begin{tabular}{ccc}
\hline Rank & Frequency per year & Description \\
\hline 1 & $<10^{-7}$ & Very unlikely \\
\hline 2 & $10^{-5} \div 10^{-7}$ & Remote \\
\hline 3 & $10^{-3} \div 10^{-5}$ & Occasional \\
\hline 4 & $10^{-1} \div 10^{-3}$ & Probable \\
\hline 5 & $>10^{-1}$ & Frequent \\
\hline
\end{tabular}

Table 4. Severity classes [13]

\begin{tabular}{cll}
\hline Rank & Severity class & Description \\
\hline 1 & Negligible & No bodily harm \\
\hline 2 & Marginal & $\begin{array}{l}\text { Slight bodily harm and/or slight damage to the technical } \\
\text { device }\end{array}$ \\
\hline 3 & Critical & $\begin{array}{l}\text { Serious bodily harm and/or serious damage to the } \\
\text { technical device }\end{array}$ \\
\hline 4 & Catastrophic & $\begin{array}{l}\text { Fatal accident or one causing permanent loss of health } \\
\text { and/or complete destruction of the device }\end{array}$ \\
\hline
\end{tabular}

\section{RESULTS}

Table 5 presents the results of questionnaires, i.e. incidents assigned to wheelchair use situations, probability rankings for the occurrence of each incident according to both surveyed groups, and the severity of the effect for each incident.

\section{DISCUSSION}

Risk matrices (Tab. 6, 7) contain three areas each:

1) area of acceptable risk (marked in white);

2) area of acceptable conditional risk (marked in grey);

3) area of inacceptable risk (marked in dark grey).

Based on the data in Table 5, 16 hazardous situations connected with wheelchair use were identified for individuals living in non-urban areas, and were placed in respective areas of the risk matrix (Tab. 6).
Sixteen pairs of wheelchair use situation-incident were assigned to 2 areas: 4 to the area of unacceptable risk (marked in dark grey) and 12 in the area of acceptable conditional risk (marked in grey). Combinations of wheelchair use situations and potential hazards within the area of acceptable risk were disregarded (area marked in white).

A similar procedure was adopted for city dwellers (Tab. 7). 14 hazardous wheelchair use situations were identified.

In the case of residents of a city, similar results were recorded, with the difference consisting in the fact that 2 pairs ((Exp. 6) - (Inc. 5) and (Exp. 6) - (Inc. 1)) from the area of medium risk for residents of non-urban areas, fell within the area of acceptable risk in the case of city dwellers.

\section{CONCLUSIONS}

As a result of the analysis of risk associated with the use of an active wheelchair with the application of PHA in the area of medium risk:

- according to residents of non-urban areas, 12 hazards were identified;

- according to residents of a city, 10 hazards were identified.

The character of differences between the 2 analysed groups seems to indicate that in non-urban areas the problem is connected with mobility over a non-hardened surface.

Moreover, four wheelchair use situations were identified, in which unacceptable risk for wheelchair users is observed (dark grey area in Tab. 5). They were identical for both groups (Tab. 8).

The situations mentioned in Table 8 need not only be included in the riding technique courses or incorporation of respective information in manuals for wheelchair users, but also in design changes in wheelchairs.

The list of incidents presented in this study, connected with wheelchair use situations together with the estimated level of risk, may be useful when designing active wheelchairs, writing manuals for wheelchair users, and learning the technique of riding an active wheelchair. Based on the recorded results, the conclusion may be drawn that modern active wheelchairs used by individuals living in non-urban areas are not completely safe in terms of their basic functions. Several design changes are still required to improve user safety at identical mobility ${ }^{2}$. A solution may be provided by specialised design - each individual with serious walking limitations should be equipped with several types of devices which may be used alternately, depending on a specific wheelchair use situation (e.g. wheelchair for transport outdoors, wheelchair for sport and recreation, wheelchair for indoor mobility, etc.). Another way to reduce the risk may be increasing education and training of wheelchair users $[3,6,15,16]$.

2. Similar conclusions have been presented in other publications, e.g. [7], [9], [14]. 
Table 5. Potential hazards for the user together with probability and effects of its occurrence

Wheelchair use situation

Potential hazard

\begin{tabular}{cc}
\multicolumn{2}{c}{$\begin{array}{c}\text { Probability ranking of incident } \\
\text { occurrence }(1-5)\end{array}$} \\
\hline $\begin{array}{c}\text { According to } \\
\text { respondents living }\end{array}$ \\
$\begin{array}{r}\text { According to } \\
\text { in non-urban areas }\end{array}$ in urban areas
\end{tabular}

Severity of incident effects according to responses of all respondents

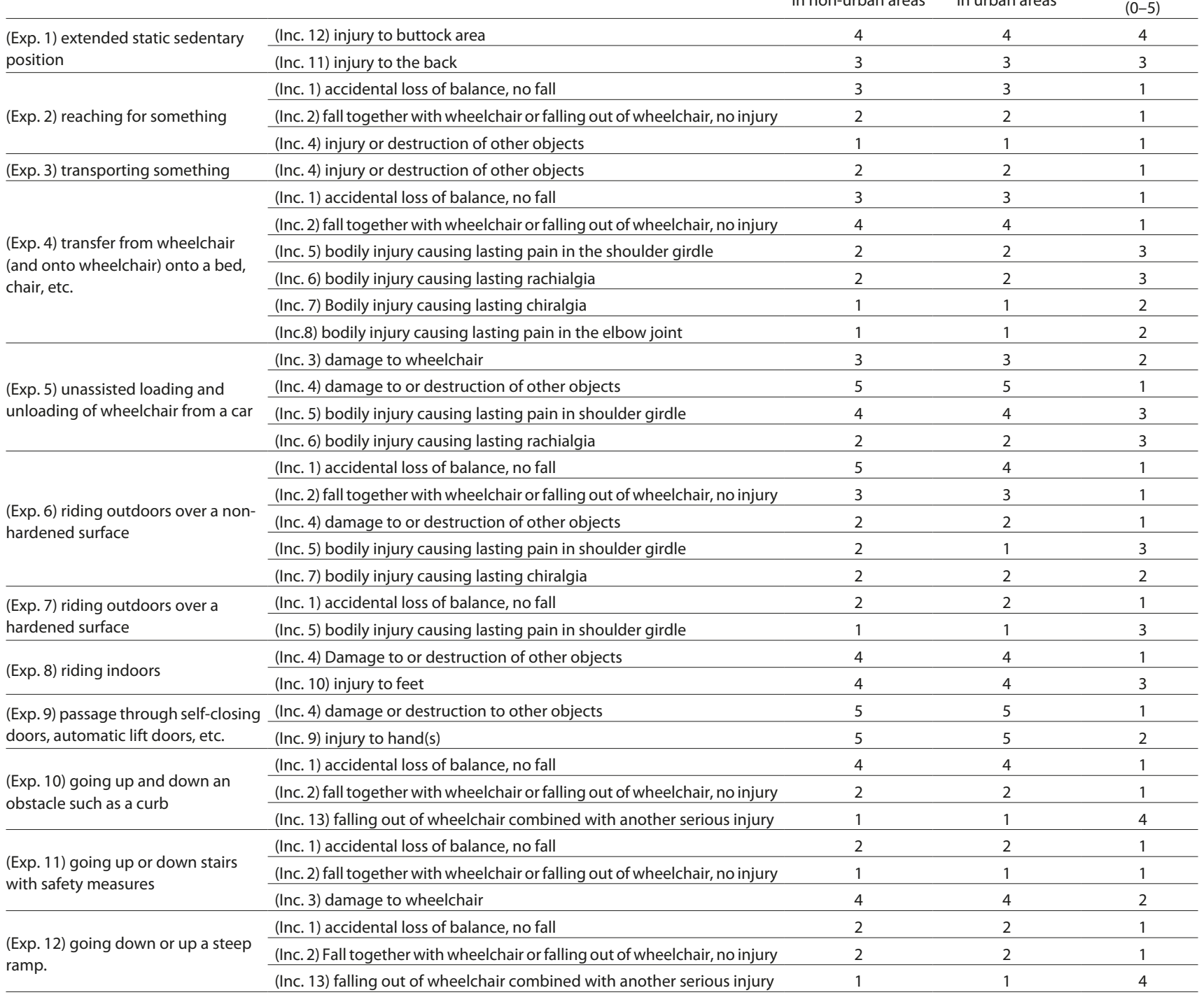

Table 6. Risk matrix - residents of rural areas

\begin{tabular}{|c|c|c|c|c|c|c|}
\hline & \multicolumn{6}{|c|}{ Frequency $\rightarrow$} \\
\hline & & 1 & 2 & 3 & 4 & 5 \\
\hline & 4 & $\begin{array}{l}\text { (Exp.10) - } \\
(\text { Inc.13) } \\
(\text { Exp.12) - } \\
(\text { Inc.13) }\end{array}$ & & & $\begin{array}{l}\text { (Exp.1) - } \\
\text { (Inc.12) }\end{array}$ & \\
\hline & 3 & & $\begin{array}{l}(\text { Exp.4) }-(\text { Inc.5) } \\
(\text { Exp.4) }-(\text { Inc.6) } \\
(\text { Exp.5) }-(\text { Inc.6) } \\
(\text { Exp.6) }-(\text { Inc.5) }\end{array}$ & $\begin{array}{c}\text { (Exp.1) - } \\
\text { (Inc.11) }\end{array}$ & $\begin{array}{l}(\text { Exp.5) - } \\
(\text { Inc.5) } \\
\text { (Exp.8)- } \\
\text { (Inc.10) }\end{array}$ & \\
\hline & 2 & & & $\begin{array}{c}(\text { Exp.5) - } \\
(\text { Inc.3) }\end{array}$ & $\begin{array}{c}(\text { Exp.11) - } \\
(\text { Inc.3) }\end{array}$ & (Exp.9) - (Inc.9) \\
\hline 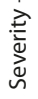 & 1 & & & & & $\begin{array}{l}(\text { Exp.5) }-(\text { Inc.4) } \\
(\text { Exp.6) - (Inc.1) } \\
(\text { Exp.9) - (Inc.4) }\end{array}$ \\
\hline & & cceptable & Possib & y acceptab & & cceptable \\
\hline
\end{tabular}

Table 7. Risk matrix - residents of city

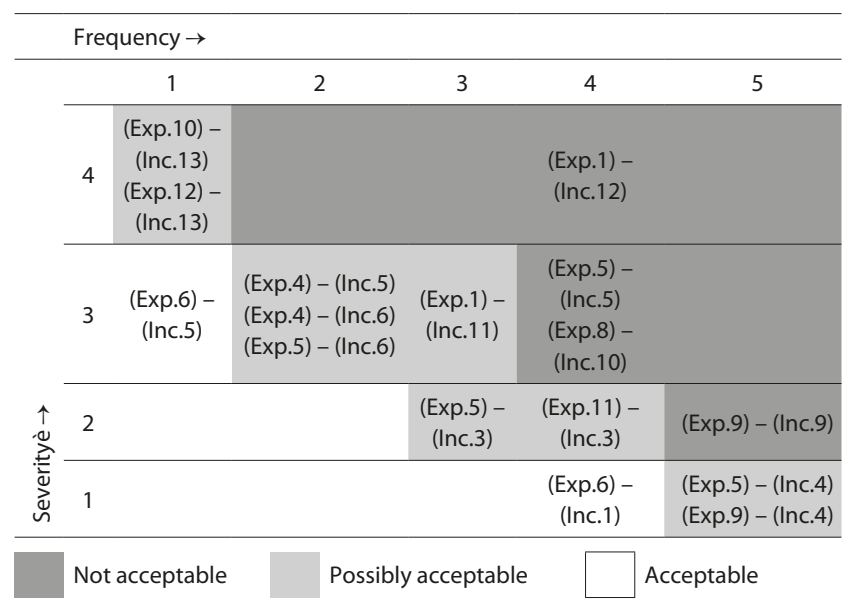


Table 8. List of situations posing the greatest risk

\begin{tabular}{|c|c|c|c|}
\hline Denoted as & Situation & Hazard & Remarks \\
\hline (Exp. 1) - (Inc. 12) & $\begin{array}{l}\text { (Exp. 1) extended } \\
\text { static sedentary } \\
\text { position }\end{array}$ & $\begin{array}{l}\text { (Inc. 12) } \\
\text { injury to } \\
\text { buttock area }\end{array}$ & $\begin{array}{l}\text { bed sores caused by } \\
\text { extended pressure } \\
\text { and/or other factors }\end{array}$ \\
\hline (Exp. 5) - (Inc. 5) & $\begin{array}{l}\text { (Exp. 5) unassisted } \\
\text { loading and } \\
\text { unloading of } \\
\text { wheelchair from } \\
\text { a car }\end{array}$ & $\begin{array}{l}\text { (Inc. 5) pain } \\
\text { in shoulder } \\
\text { girdle }\end{array}$ & $\begin{array}{l}\text { as a result of sprain } \\
\text { caused by high } \\
\text { weight of transport } \\
\text { assemblies of } \\
\text { wheelchair }\end{array}$ \\
\hline (Exp. 8) - (Inc. 10) & $\begin{array}{l}\text { (Exp. 8) riding } \\
\text { indoors }\end{array}$ & $\begin{array}{l}\text { (Inc. 10) } \\
\text { injury to feet }\end{array}$ & $\begin{array}{l}\text { collision with toes, } \\
\text { lacking the protection } \\
\text { of shoes, with } \\
\text { thresholds and other } \\
\text { indoor elements }\end{array}$ \\
\hline (Exp. 9) - (Inc. 9) & $\begin{array}{l}\text { (Exp. 9) passage } \\
\text { through self-closing } \\
\text { doors, automatic lift } \\
\text { doors, etc. }\end{array}$ & $\begin{array}{l}\text { (Inc. 9) Injury } \\
\text { to hand(s) }\end{array}$ & $\begin{array}{l}\text { collision of hand(s) } \\
\text { with doorframe or } \\
\text { doors }\end{array}$ \\
\hline
\end{tabular}

\section{REFERENCES}

1. J. Borg and C. Khasnabis, Eds., Guidelines on the provision of manual wheelchairs in less-resourced settings. Geneva: WHO Press, 2008.

2. M. Sydor, "Dobór wózka inwalidzkiego dla osoby dorosłej," [Selection of a wheelchair for an adult] Rehabil. W Prakt., vol. 3, pp. 67-69, 2013.

3. M. Sydor, Wybór i eksploatacja wózka inwalidzkiego. [Selection and operation of a wheelchair]. Poznań: Wydawnictwo Akademii Rolniczej im. Augusta Cieszkowskiego, 2003. P. 20, 25, 130.

4. P. Aldersea, "National prosthetic and wheelchair services report 1993 - 1996," College of Occupational Therapists, London, 1996.
5. R. A. Cooper, Wheelchair selection and configuration. New York: Demos Medical Publishers, 1998. P. 11.

6. R. A. Cooper, "Wheelchair research progress, perspectives, and transformation," J. Rehabil. Res. Dev., vol. 49, no. 1, p. 1, 2012.

7. R. P. Gaal, N. Rebholtz, R. D. Hotchkiss, and P. F. Pfaelzer, "Wheelchair rider injuries: causes and consequences for wheelchair design and selection," J. Rehabil. Res. Dev., vol. 34, no. 1, pp. 58-71, 1997.

8. R. Hansen, S. Tresse, and R. Gunnarsson, "Fewer accidents and better maintenance with active wheelchair check-ups: a randomized controlled clinical trial," Clin. Rehabil., vol. 18, no. 6, pp. 631-639, 2004.

9. W.-Y. Chen, Y. Jang, J.-D. Wang, W.-N. Huang, C.-C. Chang, H.-F. Mao, and Y.-H. Wang, "Wheelchair-related accidents: relationship with wheelchair-using behavior in active community wheelchair users," Arch. Phys. Med. Rehabil., vol. 92, no. 6, pp. 892-898, 2011.

10. W. J. Hurd, M. Morrow, K. R. Kaufman, and K.-N. An, "Wheelchair propulsion demands during outdoor community ambulation," J. Electromyogr. Kinesiol., vol. 19, no. 5, pp. 942-947, 2009.

11. N. Burns, K. Paterson, and N. Watson, "An inclusive outdoors? Disabled people's experiences of countryside leisure services," Leis. Stud., vol. 28 , no. 4 , pp. $403-417,2009$.

12. "Medical Devices - Application of risk management to medical devices," Technical standard PN-EN ISO 14971:2012E, 2012.

13. "Dependability Management - Part 3: Application Guide - Section 9: Risk Analysis Of Technological Systems," Technical standard PN-IEC 60300-3-9:1999P, 1999.

14. L. Worobey, M. Oyster, G. Nemunaitis, R. Cooper, and M. L. Boninger, "Increases in wheelchair breakdowns, repairs, and adverse consequences for people with traumatic spinal cord injury," Am. J. Phys. Med. Rehabil., vol. 91, no. 6, pp. 463-469, 2012.

15. H.-Y. Liu, R. Cooper, A. Kelleher, and R. A. Cooper, "An interview study for developing a user guide for powered seating function usage," 2013.

16. S. M. Hosseini, M. L. Oyster, R. L. Kirby, A. L. Harrington, and M. L. Boninger, "Manual wheelchair skills capacity predicts quality of life and community integration in persons with spinal cord injury," Arch. Phys. Med. Rehabil., vol. 93, no. 12, pp. 2237-2243, 2012. 